\title{
Digitizing the Undigitized: Converting Traditional Archaeological Records into Computerized, Three-Dimensional Site Reconstruction
}

\author{
Nira Alperson-Afil \\ Institute of Archaeology, Martin (Szusz) Department of Land of Israel Studies and Archaeology, Bar-Ilan University, \\ Ramat Gan, Israel \\ Email: nira.alperson-afil@biu.ac.il
}

How to cite this paper: Alperson-Afil, N. (2019) Digitizing the Undigitized: Converting Traditional Archaeological Records into Computerized, Three-Dimensional Site Reconstruction. Journal of Geographic Information System, 11, 747-765.

https://doi.org/10.4236/jgis.2019.116045

Received: November 3, 2019

Accepted: December 24, 2019

Published: December 27, 2019

Copyright $\odot 2019$ by author(s) and Scientific Research Publishing Inc. This work is licensed under the Creative Commons Attribution International License (CC BY 4.0).

http://creativecommons.org/licenses/by/4.0/

(c) (i) Open Access

\begin{abstract}
Archaeological excavation involves disintegration, removal, and reassembly of the archaeological record; as such it is considered by many to be an unrepeatable, destructive activity. This perception has contributed to an advancement in archaeological practice, namely, the development of computerized recording systems that digitally record archaeological excavations spatially and volumetrically during fieldwork. This paper is concerned with those archaeological sites where digital field recording has not been done. These sites, recorded by traditional methods, should not be excluded from attempts to restructure the spatial, volumetric, and stratigraphic archaeological data. A thorough methodology for the conversion of traditional records into digitized data is presented, including the detailed procedures required for threedimensional plotting of recorded data-both the excavated material and the drawn site maps and cross-sections. Finally, the use of these methods is demonstrated on a complex Early to Middle Pleistocene site, illustrating the benefits of digitization and three-dimensional reconstruction in resolving stratigraphic and spatial questions.
\end{abstract}

\section{Keywords}

Digital Archaeology, Geographic Information Systems, Archaeological Recording Methods, Three-Dimensional Reconstruction Model

\section{Introduction}

An important part of archaeological excavation is recording the stratigraphic 
and spatial properties of component parts of a study area in order to remove them in the reverse order to which they were deposited [1]. The disintegration, removal, and reassembly of the archaeological record are thus considered by many to be unrepeatable, destructive activities (e.g., [2] [3] [4]). This perception has contributed to an advancement in archaeological practice, namely, the development of computerized recording systems that digitally record archaeological excavations spatially and volumetrically ([5] [6] and references therein). At present, computer-based technologies are incorporated into many archaeological field projects, with spatial documentation and measurement being carried out during actual excavation using onsite digital recording methods (Global Navigation Satellite Systems (GNSS), Unmanned Aerial Vehicles (UAVs), and total stations). These make possible the precise conversion of recorded archaeological data into three-dimensional models of excavated contexts, often incorporating the databases of analyzed archaeological material as well (e.g., [6]-[11]).

This paper discusses a methodology for the digital reconstruction of archaeological contexts excavated using traditional recording methods. Although they do not produce digital records, the traditionally derived records from such excavations can be carefully converted into digital data to generate a computerized, three-dimensional reconstruction of the site. Archaeological contexts excavated in the past, particularly those to which access is no longer feasible, can benefit from such reconstructions in attempts to resolve stratigraphic, volumetric, and spatial questions.

Spatial reconstructions require the provenance of the excavated material so that features and artifacts can be plotted spatially. However, the initial steps of all archaeological research are carried out in the field, where various considerations dictate the pace, extent, scale, and resolution of both excavation and data recording methods. Thus, even though most archaeologists share a similar objective during fieldwork (namely, to find a contemporaneous association between artifacts and features within an undisturbed occupation episode), the methods of excavation, retrieval, and recording vary among different scholars, site types, and archaeological periods. This becomes even more troublesome when dealing with data from longstanding excavations, where excavation and documentation techniques do not follow comparable conventions. In addition, when attempting spatial reconstructions, the essential continuous visibility of the exposed surfaces is often hampered by limitations imposed by archaeological fieldwork. Baulks, for example, preserve elongated segments of the archaeological site, whereas test pits or trenches leave small, deep voids within the excavated area. Also, clear stratigraphic assignment is often feasible only after the excavation is in progress, resulting in excavated material for which stratigraphic assignment is uncertain. Similarly, relationships between different stratigraphic units (e.g., one cuts or fills another, as with post-holes) may only be fully understood in the post-excavation analysis of all data from a site.

The computer plotting methodologies discussed in this paper make it possible 
to overcome such obstacles through three-dimensional reconstruction of the excavated area. Prior to discussing these methodologies, however, the issue of field recording should be addressed. Clearly, in order to restructure the excavated area digitally, it is essential that field illustrations (e.g., sections, plans, field maps) and the archaeological material retrieved from the site be recorded according to a comprehensive spatial context-either a conventional geographic grid (e.g., national coordinate grids, latitude and longitude coordinates) or a local reference specially designed for the excavated area (e.g., an artificial grid or temporary benchmarks). Such general spatial recording incorporates various spatio-temporal units of activity (e.g., context, locus, square), distinguished horizontally and vertically from each other.

Thus, the paper will first explore the variety of archaeological recording methods and later suggest different approaches to the conversion, digitization, and plotting of the archaeological data. Finally, the use of these methods is demonstrated on the Early-Middle Pleistocene site of Gesher Benot Ya'aqov, illustrating the benefits of digitization and three-dimensional reconstruction in resolving stratigraphic and spatial questions.

\section{Field Recording}

The foundations of archaeological recording methods were laid down by Wheeler [12] and Kenyon [13], who formulated and promoted the notion of the "grid-square" method (also known as the Wheeler-Kenyon method). This method is based on using a $5 \times 5 \mathrm{~m}$ grid, leaving standing baulks between the excavated squares. These baulks create sections, which both Wheeler and Kenyon used as basis for stratigraphic analysis. The widespread adoption of the grid-square method is a significant step in the history of field recording and of intra-site archaeological studies, as it ensures that grid-square data can be easily transformed into grid-based geographic information systems. Currently, there is great variation in the size of the grid employed, which can range from $1 \times 1$ to 10 $\times 10 \mathrm{~m}$. Sub-squares are also occasionally used to further subdivide the unit of excavation and achieve greater precision.

In 1975, the "single-context" recording system was introduced in response to growing pressures of urban archaeology and salvage projects [14]. The aim of this recording system was to simplify and expedite the time-consuming process of field recording. In the "single-context" method, each excavated context is defined and recorded as a separate unit, usually using pro-forma sheets filled in by the individual excavators for each context that they identify [2]. All archaeological artifacts are then retrieved according to their contextual information and not their grid-based coordinates. Thus, reconstructing the exact original provenance of artifacts within a context becomes impossible. Furthermore, since each context is individually defined, excavation units are rarely consistent and vary in extent, depth, etc., therefore being highly incomparable to one another; this further complicates site reconstruction and spatial analysis. The context is thus a primary unit for recording and analysis, similar to the locus-basket method. 
Variations in recording methods not only appear between different sites (or archaeological periods), but can easily occur within a single site, especially when dealing with complex, long-term excavations. This mixture of methods often results in incompatible recorded data on artifacts and features of a single excavation; some items are recorded according to locus or context, some according to grid-square or sub-square, and others according to $\mathrm{X}, \mathrm{Y}$, and $\mathrm{Z}$ coordinates. This variability in recording requires that attempts to spatially reconstruct and analyze the excavated material be preceded by a plotting procedure in which the excavated material and its associated illustrations, plans, and sections are converted into a cohesive and unified dataset of geographical information. Geographic information software makes such conversion feasible. This paper uses Geographic Information Systems (GIS) as the main method for spatial reconstruction and analysis. Since GIS provides the ability to store, visualize, and, most importantly, analyze geographical and spatial information, it has become a powerful tool for the study of archaeological spatial data during the last three decades [15] [16] [17]. The ArcGIS software package comprises software and geographical data for capturing, managing, analyzing, and displaying all forms of geographically referenced information. One part of the package, ArcMap $\left(\right.$ ESRI $\left.^{\circ} \operatorname{ArcMap}^{\mathrm{TM}}\right)$, can be used for spatial display and analysis of two-dimensional archaeological data; another, ArcScene (ESRI $\operatorname{ArcScene}^{\mathrm{TM}}$ ), can be used for three-dimensional reconstruction.

\section{Digitization and Plotting of Archaeological Data}

When they finish an excavation, archaeologists return from the field with an assortment of recorded data. These include artifacts recorded and collected in the field and a variety of drawn sections, plans, and field maps. Below are two different approaches to the digitization of these two types of data.

\subsection{Converting Field Records of Artifacts}

The optimal recording method, as far as reconstructing the provenance of artifacts is concerned, would surely be one in which items are retrieved in the field with their precise $\mathrm{X}, \mathrm{Y}$, and $\mathrm{Z}$ coordinates. In such cases, all items can be easily plotted on a GIS map, corresponding either to a conventional grid or to an artificial one, representing the grid of the site studied. Yet because of variability in recording methods, as well as the various constraints imposed during excavation (discussed above), most archaeological finds are retrieved with a general spatial reference, which often includes an excavated unit (e.g., a context, locus, and/or grid location) and spit (a range of depths within the excavated unit). Such spatial recording allows the representation of only relative frequencies of items per excavated unit. However, other spatial analyses, such as density maps, may necessitate measuring the distances between features and thus require depiction of the data as distinct points. In such a case, a careful, conscientious decision should be made as to how and with which plotting principles to manipulate the data. 
Generally, three different approaches can be used: 1) point-plotting all items originating in a specific excavated unit at one spot, in the center of the excavated unit; 2) randomly distributing the items within the excavated unit; and 3) uniformly distributing items at fixed intervals within the excavated unit (Figure 1). The choice of an appropriate method depends primarily on the aims of the spatial analysis. Thus, plotting all items in a specific square in the center of the square is sufficient if one is examining relative frequencies across a given space, but is inadequate for the production of point-plotted distribution maps.

When using random distributions, point-plotted maps appear to be more "realistic" than those of uniform distribution. Research has shown that assigning a random spatial reference within an excavated area can provide a reliable, statistically identical representation of the spatial distribution of artifacts [18]. Taking this into consideration, common programs such as Microsoft Access or Microsoft Excel can easily be used to assign new, random coordinates within a given excavation unit, thus allowing spatial analysis. Random distributions may result in artificial "clusters" of material that may affect further analyses such as density maps and cluster analyses. Generally, however, the different plotting methods do not have a major effect on simple density analyses (Figure 2).

(a)

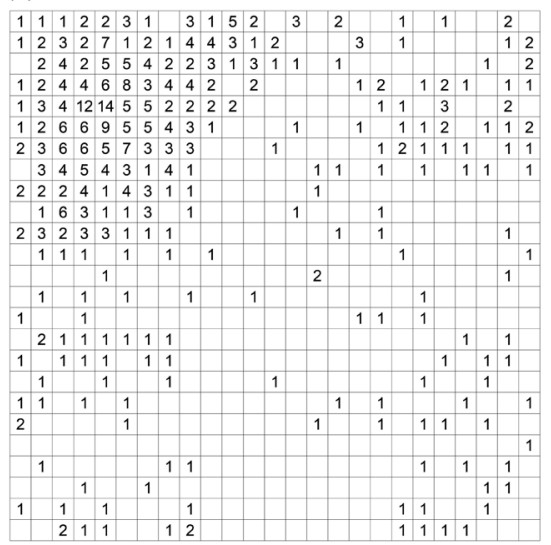

(b)

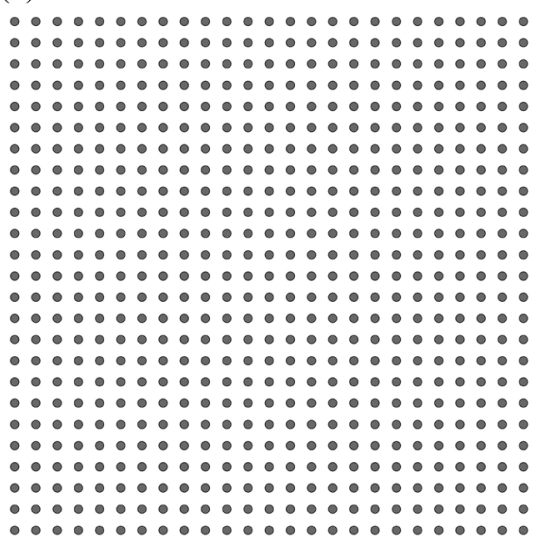

(c)

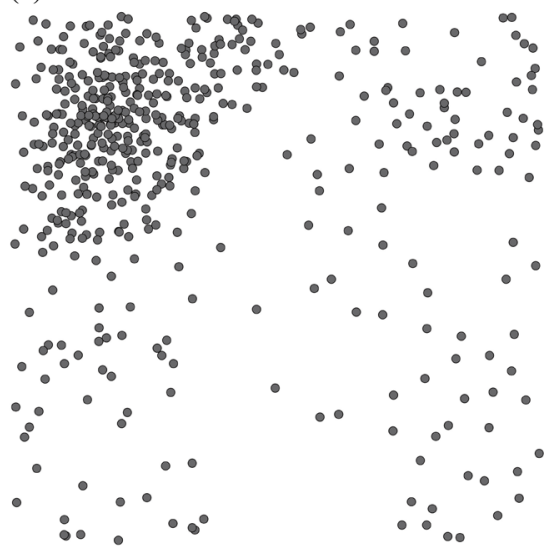

(d)

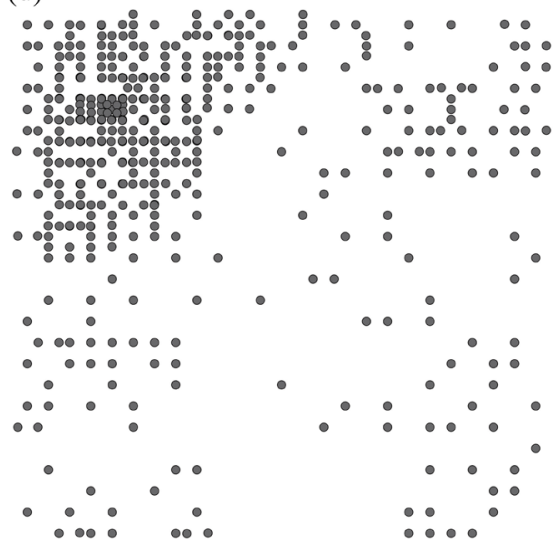

Figure 1. Three approaches to plotting (b-d), illustrated in a $25 \mathrm{~m}^{2}$ grid: (a) grid with number of recorded artifacts; (b) central plotting; (c) random plotting; (d) uniform plotting. $\mathrm{N}=500$ "artifacts" recorded within 625 grid cells. 
(a)

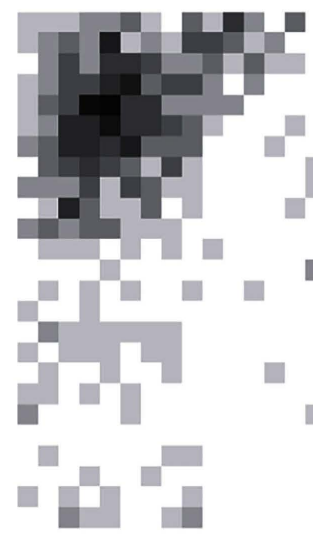

(b)

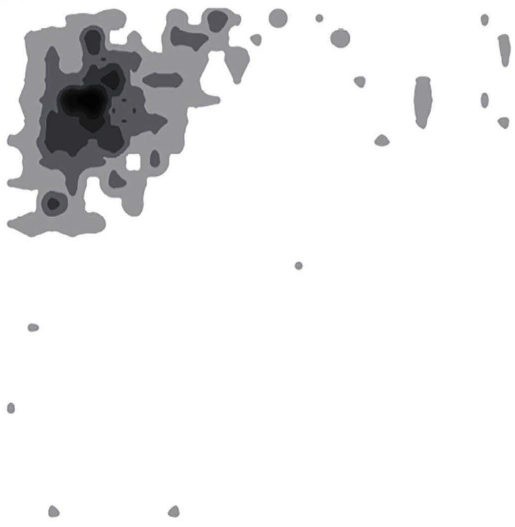

(c)

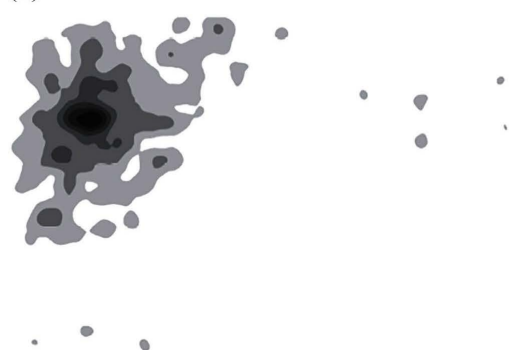

(d)

Figure 2. Density maps produced with different plotting methods (data as in Figure 1): (a) Raster representation of relative frequencies per excavated grid square (Figure 1(a)); (b) Kernel density map of centrally plotted data; (c) Kernel density map of randomly plotted data; (d) Kernel density map of uniformly plotted data.

\subsection{Digitization and Plotting of Sections and Field Maps}

In addition to artifacts recorded and collected during excavation, archaeologists return from the field with a variety of recorded data. These include excavation diaries, individual excavation sheets (e.g., pro-forma sheets), sections, general site plans, plans of individual excavation areas, and field drawings of exposed surfaces or of specific features and installations. As previously stated, it is essential for all these records to adhere to a shared spatial reference so that their spatial relationships-horizontal (two-dimensional) and vertical (three-dimensional) can be established. Prior to the computerized plotting of these data, it is the excavator's job to determine which records are of relevance to the desired reconstruction and to provide the information required for the reconstruction.

The selected plans should undergo a digitization process in which all field drawings are scanned to raster format (JPG, TIFF), and later traced using drafting software to create a vector drawing. Through the digitization process, each raw archaeological data (stratigraphic as well as spatial units) is converted into digital form for later spatial analysis using spatial analysis software. The example 
below used AutoCAD LT, a commercial computer-aided design (CAD) and drafting program developed and marketed by Autodesk. The native file format of AutoCAD LT is dwg., which serves as the standard for CAD data interoperability, particularly for 2D drawing exchange.

In the example below, computerized plotting is further complicated by the fact that the archaeological levels are tilted due to tectonic activity and tilting of the entire package of sediments at the site. Such circumstances may be relevant to other sites as well, where the occupational surface is sloped or uneven rather than horizontal, and should be plotted and analyzed as such.

\section{Restructuring Gesher Benot Ya'aqov}

Gesher Benot Ya'aqov (GBY) is an Early to Middle Pleistocene archaeological site located in the course and on the banks of the Jordan River, Israel. Excavations exposed a 34-meter depositional sequence in which 15 archaeological levels have been recorded. The GBY sequence consists of a reversed-polarity zone overlaid by a normal-polarity zone, correlated with the 0.79 Ma MatuyamaBrunhes chron boundary; the entire depositional sequence is assigned to OIS $18-20$ and its estimated duration is 100,000 years. Archaeological data indicate that Acheulian hominins regularly occupied the margins of Paleo Lake Hula, where they produced stone tools [19], used and controlled fire [20], processed meat [21], and gathered a vast range of plant food, which has been preserved due to the waterlogged environment [22]. Tectonic activity on the transform fault of the Dead Sea Rift has resulted in the tilt of the strata at the site. The tilted archaeological horizons are embedded within a generally fine-grained sedimentary sequence, documenting rapid shifts in an abundance of carbonate and organic materials typical of a low-energy, fluctuating lake margin environment. The site was excavated in seven field seasons between 1989 and 1997, using traditional recording methods [19].

\subsection{Field Recording}

Excavation of GBY was carried out in three main areas, all located on the eastern bank of the Jordan River (Figure 3). A horizontal $1 \times 1 \mathrm{~m}$ grid was constructed above the excavated surfaces, corresponding to the Israeli Transverse Mercator (ITM) geographic coordinate system. The ITM was used to position and orient the physical grid in the study area, serving as a reference system for the spatial location of all finds originating in the excavations. During the first two field seasons (1989 and 1990) the grid was simply laid down on the horizontal surface of the excavation area. As differences in elevation (caused by exposure of the sediments along the strike and dip) were jeopardizing the accuracy of the grid, a suspended grid system was applied to the entire excavation area starting with the 1991 field season. The grid system formed units of $1 \mathrm{~m}^{2}$, each subdivided equally into four sub-squares. The southwestern corner of each square was the zero point for readings of $\mathrm{x}$ and $\mathrm{y}$ coordinates. Strings with fishing weights attached to their ends (plumb lines) were used to form the four corners of each square 
meter and to mark the boundaries of the square for each grid on the tilted horizons (Figure 3).

To allow for observation of the stratigraphic sequence, six trenches were mechanically excavated by a backhoe, perpendicularly to the strike of the bedding.

Cross-sections: Two types of cross-sections, both to a scale of 1:10, were part of the routine excavation and recording methodology. The first were drawn in accordance with the grid system, so as to make possible reconstruction of the configuration of the entire excavated volume. The second were drawn perpendicularly to the layers in order to identify the detailed relationship between the various superimposed levels in Areas B and C. These cross-sections were based on an imaginary horizontal line from which measurements were taken perpendicularly all along the tilted excavation surfaces (Figure 3). Following the "peeling" of the archaeological horizon and the exposure of the underlying one, the same procedure was repeated, thus forming an accumulative cross-section. These are "phantom" cross-sections that do not exist as a standing profile.
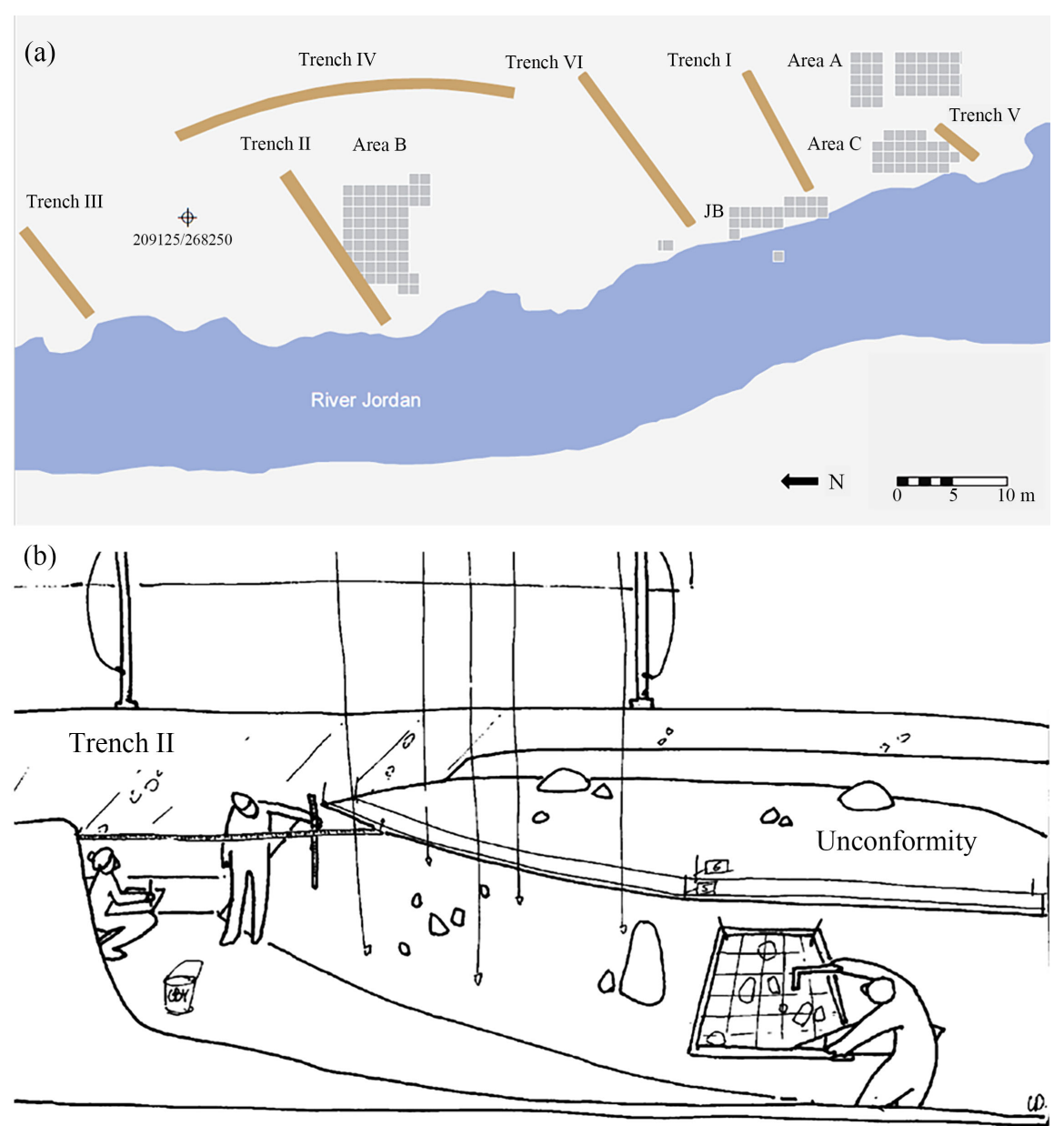

Figure 3. (a) The GBY study area: map of trenches and excavation areas; (b) Schematic illustration of Area B demonstrating different methodologies used during field drafting: in the foreground a drawing of an exposed surface (field map) and in the background a drawing of cross-sections perpendicular to the layer. Note the freestanding grid and the strings marking the strike of the levels. 
Lateral exposure: Excavation started with the removal of recent deposits (the unconformity), including redeposited Pleistocene material underlying recent sediments, in order to expose the Lower-Middle Pleistocene bedding. The horizontal (plan view) section of the underlying Pleistocene deposits was drawn to document the stratigraphy. After exposure of the Pleistocene sediments and their stratigraphy, the excavation of the deposits began with the exposure of the tilted beds (each observed, for enhanced control, in the adjacent trench as well). The archaeological horizons were all exposed along the strike and dip of the layer/level. Upon completion of the lateral exposure of each artifact-bearing horizon, the finds were mapped and photographed, and their spatial provenance was recorded before removal.

$\mathrm{X}, \mathrm{Y}$, and $\mathrm{Z}$ recording: The complete spatial reference $(\mathrm{X}, \mathrm{Y}$, and $\mathrm{Z}$ ) was recorded for "coordinated pieces" that consist mostly of items larger than $2 \mathrm{~cm}$. Other items retrieved during excavation, the "uncoordinated pieces," were labeled according to the spatial reference of the spit (i.e., excavated unit/subsquare and elevation range). Such items can thus be located with a precision of $0.5 \times 0.5 \times 0.05 \mathrm{~m}$. In addition to material retrieved during excavation, the entire excavated volume of sediments representing the archaeological horizons was wet-sieved during fieldwork using a $2 \mathrm{~mm}$ sieve. The wet-sieved sediments were then bagged with their recorded spit location. Sorting of the sieved sediments yielded rich and varied assemblages, such as fruits, seeds, grains, bones and teeth of micromammals, fish, and crabs, specks of charcoal, and stone objects ranging in size from 2 to $20 \mathrm{~mm}$.

Elevations of surfaces and excavated items were read in reference to sea level, based on a fixed excavation datum (benchmark). Elevations were measured with folding carpenter's rulers and were determined with the use of a string line and line level attached to a nearby datum stake referenced to the site's benchmark. Elevations were measured on the exposed tilted surface of each excavation unit (a $0.5 \mathrm{~m}^{2}$ sub-square to a depth of $5 \mathrm{~cm}$ ) at the beginning and end of each excavation session. Initial and final measurements were taken on the tilted exposed surfaces and on the same points of each square: the northeastern (uppermost) point and the southwestern (lowermost) point, each marked on the excavator's sheets. Two elevation readings were also taken for each find (stone, including natural pieces, bone, and wood) larger than $2 \mathrm{~cm}$, the first on top of the item and the second on the surface below it after its removal, thus providing the thickness of the item. Top and bottom elevations of these items were also marked on the map of each of the archaeological horizons.

Mapping archaeological horizons: The exposed occupational levels were mapped in detail to a scale of 1:5. The mapping was done as if perpendicularly to the tilted artifact-bearing horizon, a view that is consequently not related to the grid system. Correlation of the grid to each of the maps was accomplished by marking the location of each plumb line (representing the corners of each square meter on the grid) on the tilted surface. In cases of superimposed artifact surfac- 
es (levels) such as those of Layer II-6, several lines were marked on the horizontal surface of the unconformity above the excavated surface (Figure 3). Each of these lines, delineated by parallel white strings, marked the location of an archaeological horizon and its strike. Whenever possible, a preliminary identification of each item (handaxe, cleaver, flake, core, bone, or piece of wood, usually of large dimensions) was recorded on the map.

\subsection{Converting Field Records to Geographical Information}

The analyzed assemblages from GBY are organized in two different types of Access databases. In the first, which consists mostly of items larger than $2 \mathrm{~cm}$, each database row incorporates the attributes of a single item. The second type of database consists only of small items, retrieved through sorting of the sieved sediments; here, each row incorporates the total content of a sediment unit (i.e., of an excavated spit). The difference between these two databases required separate procedures in order to convert the data into spatially manageable geographical information; more specifically, the database in which the entire content of an excavated spit was depicted in a single row had to be converted into a "single-record row" database. This conversion made possible the spatial plotting of all items, as discussed below.

For each excavated item, the recorded data includes stratigraphic assignment and provenance recording (either a full $\mathrm{X}, \mathrm{Y}, \mathrm{Z}$ reference or a $0.5 \times 0.5 \mathrm{~m}$ quadrant and a range of elevations). Many items were retrieved with a general spatial reference, either during excavation or throughout the sorting of the wetsieved sediments. The spatial reference for these includes the $\mathrm{X}$ and $\mathrm{Y}$ quadrant $(0.5 \times 0.5 \mathrm{~m})$ and depth of spit (with $\mathrm{Z}$ being a range of depths). Such spatial recording allows only the representation of relative frequencies of lithic items per excavated unit. Other spatial analyses, such as the creation of a density map, would necessitate measuring the distances between features and thus require that the data be depicted as distinct points.

Using the Visual Basic language within Microsoft ${ }^{\circ}$ Access, items with a general spatial reference were given a new reference point within their recorded subsquare. This procedure made it possible to plot each of the excavated finds and included the following stages: Each archaeological layer was treated independently within a separate database. The database was then sorted according to the recorded excavation units of the particular layer. Each of these excavation units had a defined excavated area $(0.5 \times 0.5 \mathrm{~m}$ sub-squares or $1 \times 1 \mathrm{~m}$ squares $)$, from which a certain number of items was retrieved. This area (a) was then divided by the maximum number of items retrieved from that area $(n)$ so that each item could be plotted separately within an $a / n$ area $(\delta)$. For example, if a given excavated area measuring $1 \mathrm{~m}^{2}(a=1)$ has 100 items $(n=100)$, and these 100 items are distributed evenly within the $1 \mathrm{~m}^{2}$ area, each item occupies an area of 1/100 $\mathrm{m}^{2}(\delta=0.01)$. The new reference point for each of these items is defined as the southwestern corner of each $\delta$ cell, so that: $a=\sum \delta_{1-n}\left(\delta_{1}+\delta_{2}+\delta_{3}+\delta_{4} \ldots \delta_{n}\right)$. 
This procedure makes it possible to plot the items uniformly within their recorded spit, ensuring that the newly plotted data are as consistent as possible with the recorded data, to the degree of precision of a sub-square.

Several procedures required a three-dimensional representation of the data (e.g., assigning a stratigraphic classification, as described below). In these cases, the vertical position ( $\mathrm{Z}$ coordinate) of the items was essential. As previously discussed, many "uncoordinated" pieces were retrieved from the field with a recorded range of elevations. Due to the tilt of the archaeological exposures, elevations were recorded in two corners of the excavated unit, northeastern (NE) and southwestern (SW), at the beginning (TOP) and end (BOTTOM) of each excavation session (defined as a $5 \mathrm{~cm}$ spit of excavated material). In order to convert these elevations into a single $\mathrm{Z}$ point, the average of the recorded elevations was calculated so that the new $\mathrm{Z}$ point represented the elevation at the center (both vertical and horizontal) of the excavated unit: NEW $\mathrm{Z}=\{[(\mathrm{NETOP}+$ NEBOTTOM $) / 2]+[($ SWTOP + SWBOTTOM $) / 2]\} / 2$.

\subsection{Digitization and Plotting of Cross-Sections and Field Maps}

The drawn archaeological data (field maps and cross-sections) was digitized using AutoCAD LT ${ }^{\circ}$ software. The digitization process included several stages:

1) Each scanned plan was treated in an individual AutoCAD file.

2) Prior to drafting, the scanned plan was resized in accordance with its actual scale.

3) Drafting on top of the scanned plans used the "layers" feature available in AutoCAD. This made it possible to assign different "layers" to distinct stratigraphic units, building a uniform cartographic legend for the site's stratigraphic units.

4) Drafting attempted to capture features as closed polygons to facilitate later analysis.

5) Once an item was drawn in AutoCAD, different attributes could be added to its table description by double-clicking the drawn feature. This made it possible to incorporate other map data into the digitized map (e.g., the catalogue number of a drawn feature, elevation, typological identification). Incorporating the catalogue number, for example, would allow for later joining of the drawn map with the analysis databases, based on their common catalogue number (Figure 4).

6) Once all features of the plan were digitized, all elements in the drawing were selected and anchored to their original recorded spatial location. This procedure involved the simple "move" and "rotate" tools available in AutoCAD. If the digitized plan was oriented properly and to scale, plotting required only one spatial reference point within the plan, which was selected and moved to its actual grid location. This point, however, had to have known $\mathrm{X}, \mathrm{Y}$, and $\mathrm{Z}$ coordinates; the $Z$ value was then determined for the entire plan.

These stages are satisfactory for horizontal, two-dimensional plans that are by 
default plotted at a uniform elevation.

Plotting three-dimensional plans (e.g., sections) requires additional procedures. The transformation from a two-dimensional depiction to a three-dimensional position requires a 3D rotation of the entire plan. The rotation axis should be one for which the accurate elevation is known.

1) When the plan is selected and the rotation axis is defined, the angle of rotation should be specified (e.g., 90 degrees when attempting to position a crosssection).

2) Other circumstances that may require non-horizontal positioning are cases where the archaeological remains are not bedded horizontally. This can be the result of an uneven occupational surface, a slope, or a tilted surface, as in the tilted layers at GBY. In such cases, the bottom elevations of the archaeological material should be recorded and the plan (field map) should be plotted according to the recorded elevations of the archaeological material (Figure 5).

Following the digitization and plotting, the individual maps and cross-sections can be assembled into a single file, either in AutoCAD or in ArcScene, to produce a complete three-dimensional model of the site (Figure 6). The converted databases of excavated artifacts can then be integrated into the model as well (Figure 6).

(a)

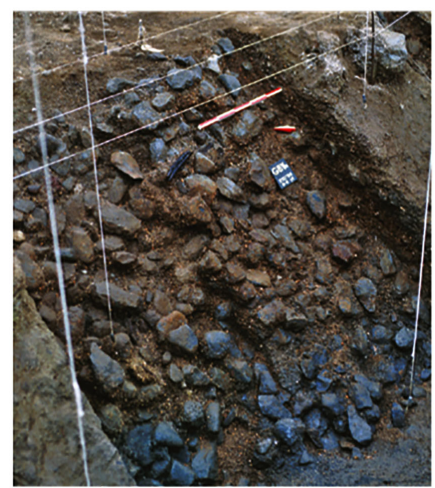

(b)

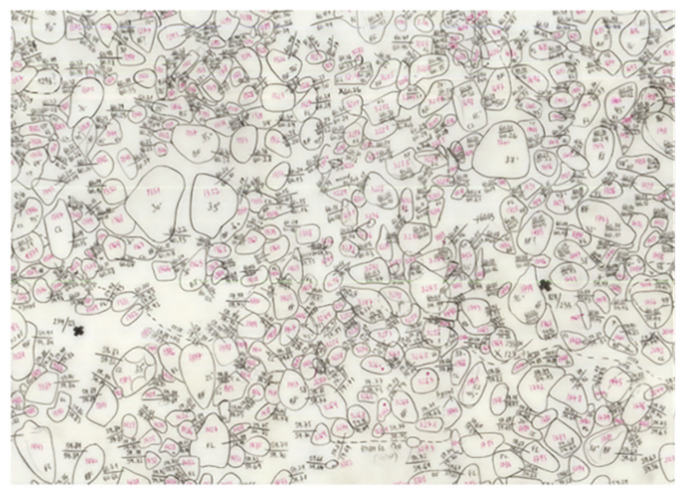

(c)

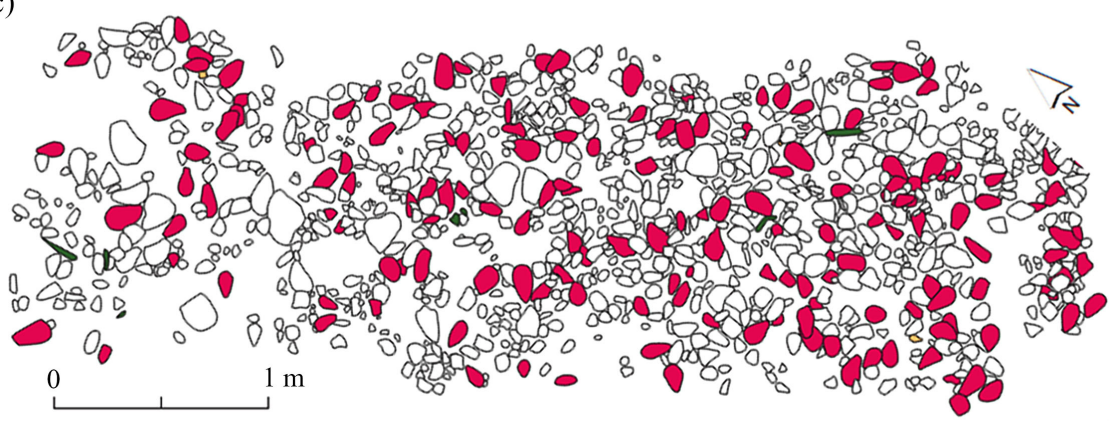

Figure 4. GBY Layer II-6, Level 4: (a) close-up view; (b) segment of the field map, facing east, with black crosses marking the corners of the grid square on the tilted horizon; (c) the field map after digitization, positioning, and joining with analysis databases (colors correspond to AutoCAD layers documenting the typological identification carried out in the field: pink for bifacial tools, white for cores and flakes, and green for wood segments). 
(a)

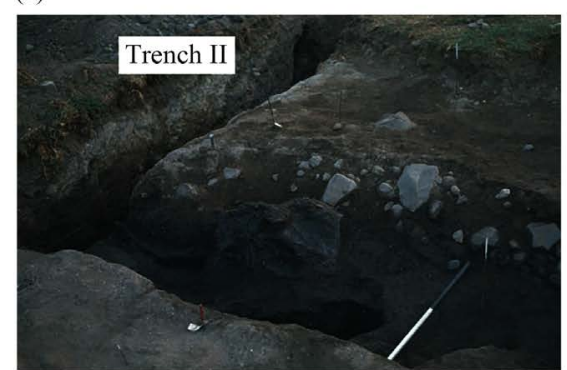

(b)

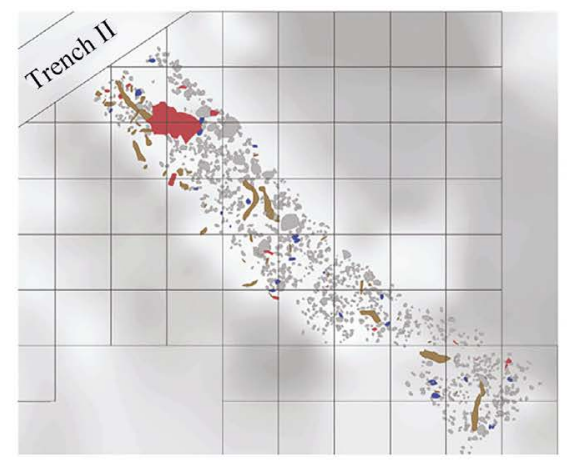

(c)

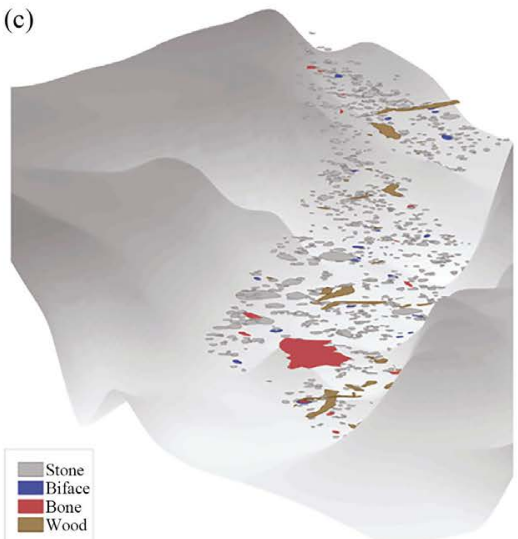

Figure 5. The elephant skull horizon of Layer II-6, Level 1: (a) During excavation; (b) The digitized field map in plan view; (c) The digitized field map in its original tilted position: view from Trench II to southeast.

\subsection{Archaeological Input}

The digital reconstruction of the excavated areas of GBY was used to illustrate the study area as well as to assess different aspects of stratigraphic, spatial, and volumetric questions.

Stratigraphic assignment: Layers I-4 and I-5 were exposed in 1989, the first season of renewed excavations, when fieldwork focused on two areas: the southeastern part of the study area (Area A) and about $45 \mathrm{~m}$ to the northwest (Area B) (Figure 3). In Area A, the tilted nature of the archaeological horizons was revealed during excavation (Figure 7). Upon the quarrying of Trench I, the observed archaeological layers were assigned individual reference names (I-4 and I-5). These two layers, observed in various sections within the excavated area, exhibited a sedimentological divergence between gray clay (I-4) and a coquina 
mixed with sandy and clayey lenses (I-5) (Figure 7). As excavation proceeded, the distinction between these two horizons became evident and material was given a definite stratigraphic assignment. However, for some of the excavated material no stratigraphic assignment was specified. These circumstances resulted in an excavated assemblage in which some of the material was recorded with a full spatial reference (i.e., excavated grid unit, range of elevations, and specific layer), while other material lacks a record of the stratigraphic assignment. In order to allow spatial plotting of the excavated material from Area A, it was necessary to determine the stratigraphic position of some of the excavated assemblages. Using ArcScene (ESRI $I^{\circ}$ ArcScene ${ }^{\mathrm{TM}}$ ), the three-dimensional data analysis software in the ArcGIS package, the entire lithic assemblage of Area A was plotted three-dimensionally and then divided into two separate stratigraphic units. The division was made possible by a "virtual" 3D surface designed to depict the tilted contact between I-4 and I-5. The outlines of this "contact surface" follow the contact lines of I- $4 / 5$ as drawn in the various field cross-sections; thus items above the surface were assigned to I-4 and items below it to I-5 (Figure 8).

(a)

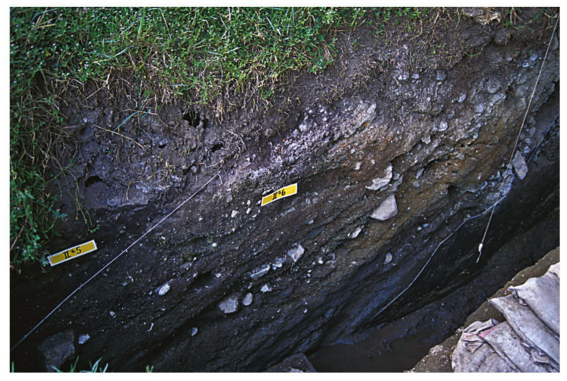

(b)

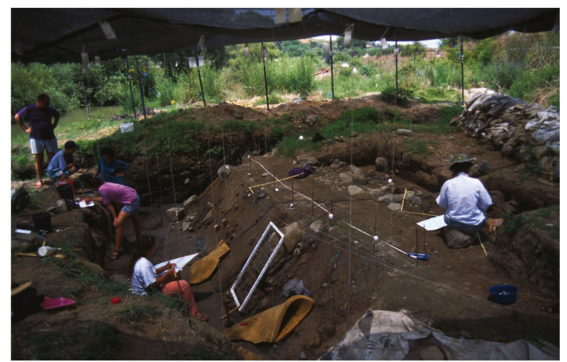

(c)

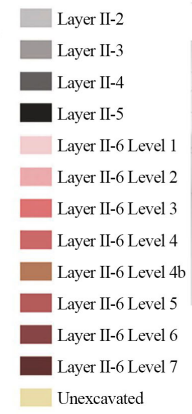

Trench II

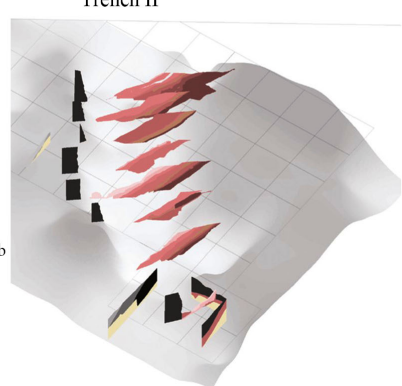

Figure 6. Area B-digitization and positioning of sections: (a) View of the northern face of Trench II; (b) General view of Area B during excavation of Layer II-1; (c) Three-dimensional view of cross-sections in Area B (view to northeast); the grey surface is the raster expression of the final elevations measured throughout the excavated area at the end of fieldwork. 

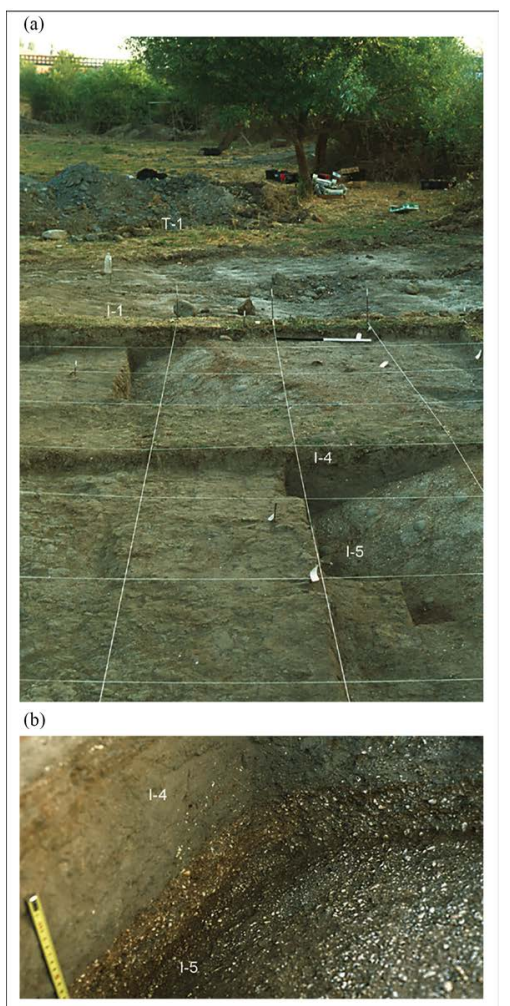

Figure 7. (a) General view of Area A looking north; (b) The stratigraphic position of Layers I-4 and I-5 as seen in a corner of an excavated square.

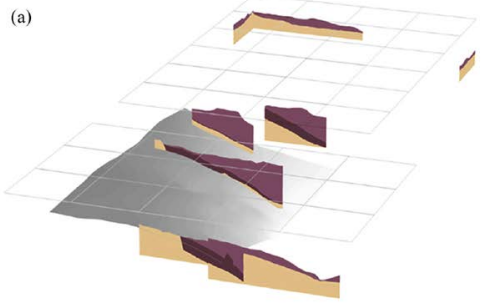

(b)
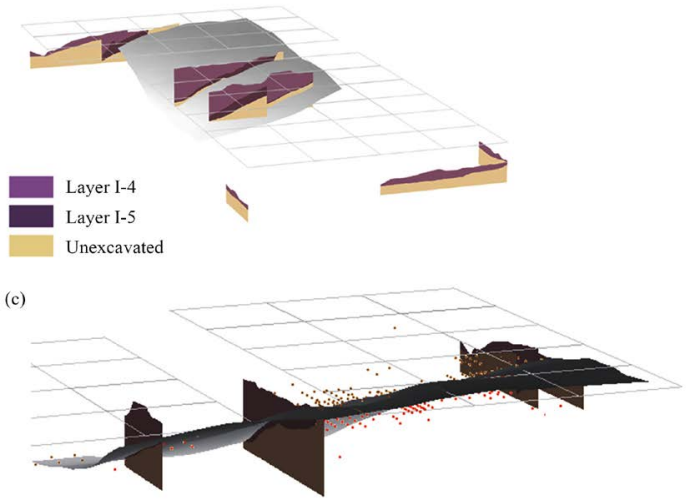

Figure 8. Three-dimensional views of the excavations and cross-sections in Area A: (a) View to the southeast; (b) View to the northwest; (c) The contact surface between Layers I-4 and I-5 and the distribution of flint flakes above (brown, Layer I-4) and below (red, Layer I-5) the surface. 
Spatial analysis: The GBY reconstruction project was used as the basis for a thorough spatial analysis of the archaeological material. This included the identification of phantom hearths and the continual use of fire at the site [23] and the identification of spatial patterning of activities [24]. The plotting of different lithic, faunal, and botanical assemblages made possible the analysis of spatial patterns within the reconstructed excavation area, using both data recorded in the field and data obtained from the analysis of the excavated material. Figure 9 illustrates the combination of different recorded data for the spatial analysis of one occupational level: Layer II-6, Level 2. This spatial analysis used a variety of recorded data, including artifacts retrieved with a general spatial reference, plotted uniformly to produce kernel density maps (of burnt flint microartifacts), databases of finds retrieved with their precise $\mathrm{X}$ and $\mathrm{Y}$ coordinates (basalt anvils in Figure 9(b), wood pieces in Figure 9(c)), and the map of the exposed surface drawn in the field.
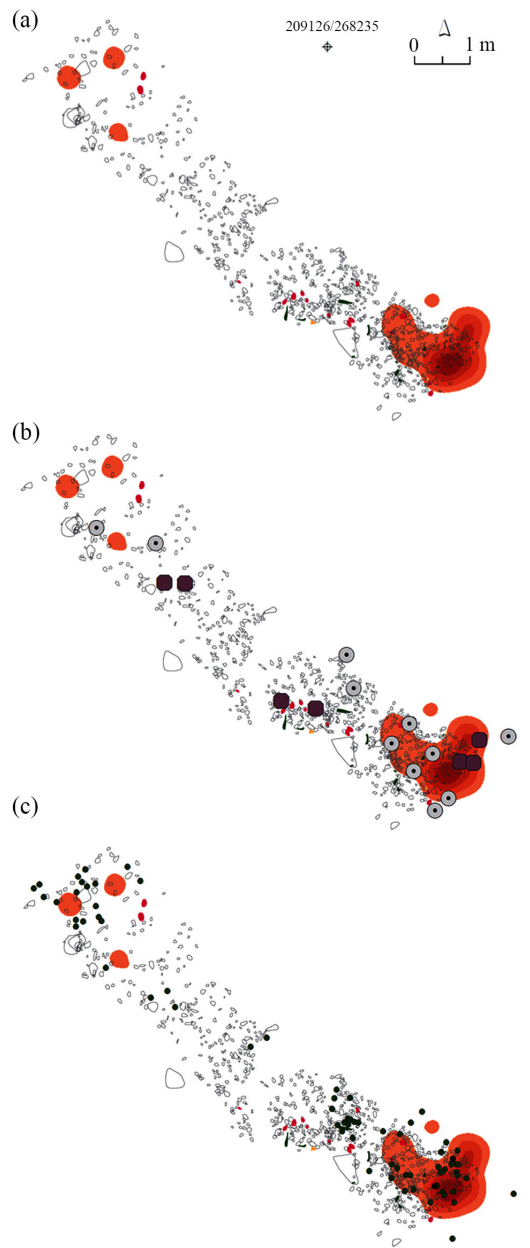

Figure 9. Layer II-6, Level 2: (a) Field map superimposed on density map of burnt flint microartifacts $(\mathrm{N}=550)$; (b) Field map superimposed on density map of burnt flint microartifacts and distribution of basalt anvils (purple squares) and basalt pitted anvils (dotted circles); (c) Field map superimposed on density map of burnt flint microartifacts and distribution of unburnt (green dots) and burnt (black dots) wood pieces. 


\section{Discussion and Conclusions}

The fact that archaeological excavation is often regarded as a destructive process contributes to continuous advancement in developing methods for recording archaeological field data. At the present time, innovative computerized methods are used sporadically in fieldwork to achieve precise conversion of recorded archaeological data into three-dimensional site models. Despite this progress, many sites are still being excavated, as in the past, using traditional recording methods and not producing digital records. This paper drew attention to the possibility of converting traditional records, too, into digital data and generating a 3D reconstruction of an archeological site. Such reconstructions are valuable for not only displaying the site graphically, but also resolving stratigraphic, spatial, and volumetric questions.

A major component of any spatial reconstruction is the method of recording, which varies among cultural periods, site types, and scholars. The plotting methodologies presented in this paper are suitable for a variety of recording methods, as well as for a variety of recording data, illustrating the feasibility of three-dimensional site reconstruction. Two key categories of recording data, available in virtually all archaeological projects, are required for an adequate three-dimensional reconstruction. The first comprises drawn material (e.g., field maps and cross-sections); the second consists of the archaeological finds themselves (e.g., artifacts, bones, and installations) removed from the site with some sort of recorded provenance. Archaeological finds are rarely retrieved with their precise $\mathrm{X}, \mathrm{Y}$, and $\mathrm{Z}$ coordinates, so plotting is required. The three suggested plotting approaches (central, random, and uniform) do not differ substantially for the purpose of simple display of artifact frequencies or densities. Other spatial questions may, however, require a point-plotted approach (random or uniform). The other category of recorded data-drawn maps and sections-provides the overall stratigraphic and spatial context of the archaeological finds. If they adhere to a shared spatial reference, these can be scanned, digitally traced, and plotted to their accurate spatial positions in order to construct a 3D model of the site. Though not used in the project presented here, photographs can be treated similarly to drawn material and can be integrated into the 3D model, provided they capture a shared spatial reference and an appropriate scale.

The case of GBY illustrated the feasibility of reconstructing a site that was excavated some 20 years ago and presents inherent structural and stratigraphic complications. The meticulous excavation methods used during fieldwork at the site provided sufficient data to make 3D reconstruction possible. In turn, this reconstruction provided a means to resolve stratigraphic uncertainties and to carry out in-depth spatial analysis.

The assertion of Roosevelt et al. that "archaeology has always been inherently real world and $3 \mathrm{D}$, yet until recently it has had to rely on $2 \mathrm{D}$ abstractions of $3 \mathrm{D}$ realities" ([6]: p. 326) is further reinforced in the present study, suggesting that even when not done during fieldwork, digitization is straightforward, feasible, and stratigraphically and spatially beneficial. 


\section{Conflicts of Interest}

The author declares no conflicts of interest regarding the publication of this paper.

\section{References}

[1] Roskams, S. (2001) Excavation (Cambridge Manuals in Archaeology). Cambridge University Press, Cambridge.

[2] Barker, P. (1993) Techniques of Archaeological Excavation. Batsford, London.

[3] Lucas, G. (2001) Destruction and the Rhetoric of Excavation. Norwegian Archaeology Review, 34, 35-46. https://doi.org/10.1080/00293650119347

[4] Tanaka, E. (2015) Heritage Destruction in Context: The Case of the Roman Mosaics from Zeugma, Turkey. International Journal of Heritage Studies, 21, 336-353. https://doi.org/10.1080/13527258.2014.964287

[5] Clarke, M. (2015) The Digital Dilemma: Preservation and the Digital Archaeological Record. Advances in Archaeological Practice, 3, 313-330. https://doi.org/10.7183/2326-3768.3.4.313

[6] Roosevelt, C.H., Cobb, P., Moss, E., Olson, B.R. and Ünlüsoy, S. (2015) Excavation Is Destruction Digitization: Advances in Archaeological Practice. Journal of Field Archaeology, 40, 325-346. https://doi.org/10.1179/2042458215Y.0000000004

[7] Benavides López, J.A., Aranda Jiménez, G., Sánchez Romero, M., Alarcón García, E., Fernández Martín, S., Lozano Medina, A., et al. (2016) 3D Modelling in Archaeology: The Application of Structure from Motion Methods to the Study of the Megalithic Necropolis of Panoria (Granada, Spain). Journal of Archaeological Science, 10, 495-506. https://doi.org/10.1016/j.jasrep.2016.11.022

[8] Howland, M.D., Kuester, F. and Levy, T.E. (2014) Structure from Motion: Twenty-First Century Field Recording with 3D Technology. Near Eastern Archaeology, 77, 187-191. https://doi.org/10.5615/neareastarch.77.3.0187

[9] Katsianis, M., Tsipidis, S., Kotsakis, K. and Kousoulakou, A. (2008) A 3D Digital Workflow for Archaeological Intra-Site Research Using GIS. Journal of Archaeological Science, 35, 655-667. https://doi.org/10.1016/j.jas.2007.06.002

[10] Morgan, C. and Wright, H. (2018) Pencils and Pixels: Drawing and Digital Media in Archaeological Field Recording. Journal of Field Archaeology, 43, 136-151. https://doi.org/10.1080/00934690.2018.1428488

[11] Stal, C., Van Liefferinge, K., De Reu, J., Docter, R., Dierkens, G., De Maeyer, P., et al. (2014) Integrating Geomatics in Archaeological Research at the Site of Thorikos (Greece). Journal of Archaeological Science, 45, 112-125. https://doi.org/10.1016/j.jas.2014.02.018

[12] Wheeler, M. (1954) Archaeology from the Earth. Clarendon, Oxford.

[13] Kenyon, K.M. (1971) An Essay on Archaeological Techniques: The Publication of Results from the Excavation of a Tell. Harvard Theological Review, 64, 271-279. https://doi.org/10.1017/S0017816000032545

[14] Spence, C. (1993) Recording the Archaeology of London: The Development and Implementation of the DUA Recording System. In: Harris, E.C., Brown III, M.R. and Brown, G.J., Eds., Practices of Archaeological Stratigraphy, Academic, London, 23-46. https://doi.org/10.1016/B978-0-12-326445-9.50008-3

[15] Doneus, M., Neubauer, W. and Studnicka, N. (2004) Digital Recording of Stratigraphic Excavations. Enter the Past. The e-Way into the Four Dimensions of Cul- 
tural Heritage: CAA 2003, Computer Applications and Quantitative Methods in Archaeology: Proceedings of the 31 st Conference, Vol. 1, Vienna, April 2003, 113-116.

[16] Harris, T.M. and Lock, G. (1990) The Diffusion of a New Technology: A Perspective on the Adoption of Geographic Information Systems within UK Archaeology. In: Allen, K.M.S., Green, S.W. and Zubrow, E.B.W., Eds., Interpreting Space: GIS and Archaeology, Taylor and Francis, London, 33-53.

[17] Kvamme, K.L. (1995) A View from across the Water: The North American Experience in Archaeological GIS. In: Lock, G. and Stančič, Z., Eds., Archaeology and Geographical Information Systems: A European Perspective, Taylor and Francis, London, 1-14.

[18] Gilead, I. (2002) Too Many Notes? Virtual Recording of Artifacts Provenance. Virtual Archaeology: Proceedings of the VAST Euroconference, Arezzo, 24-25 November 2000, 41-43.

[19] Goren-Inbar, N., Alperson-Afil, N., Sharon, G. and Herzinger, G. (2018) The Acheulian Site of Gesher Benot Ya'aqov. Volume IV: The Lithic Assemblages. Springer, Dordrecht. https://doi.org/10.1007/978-3-319-74051-5

[20] Alperson-Afil, N. and Goren-Inbar, N. (2010) The Acheulian Site of Gesher Benot Ya'aqov. Volume II: Ancient Flames and Controlled Use of Fire. Springer, Dordrecht. https://doi.org/10.1007/978-90-481-3765-7

[21] Rabinovich, R., Gaudzinski-Windheuser, S., Kindler, L. and Goren-Inbar, N. (2012) The Acheulian Site of Gesher Benot Ya'aqov. Volume III: Mammal Taphonomy: The Assemblages of Layers V-5 and V-6. Springer, Dordrecht. https://doi.org/10.1007/978-94-007-2159-3

[22] Goren-Inbar, N., Werker, E. and Feibel, C.S. (2002) The Acheulian Site of Gesher Benot Ya'aqov. Volume I: The Wood Assemblage. Oxbow, Oxford.

[23] Alperson-Afil, N. (2008) Continual Fire-Making by Hominins at Gesher Benot Ya'aqov, Israel. Quaternary Science Reviews, 27, 1733-1739. https://doi.org/10.1016/j.quascirev.2008.06.009

[24] Alperson-Afil, N., Sharon, G., Kislev, M., Melamed, Y., Zohar, I., Ashkenazi, S., et al. (2009) Spatial Organization of Hominin Activities at Gesher Benot Ya'aqov, Israel. Science, 326, 1677-1680. https://doi.org/10.1126/science.1180695 